\title{
Elevated Levels of the Pollutant PM2.5 in Crowded Subways of Cities with High COVID-19 Related Mortality- Has COVID-19 Gone Underground?
}

\author{
Baron YM* \\ University of Malta Medical School, Mater Dei Hospital, \\ Malta \\ *Corresponding author: Yves Muscat Baron, \\ University of Malta Medical School, Mater Dei Hospital, \\ Msida, Malta
}

Received: December 24, 2020; Accepted: J anuary 19, 2021; Published: J anuary 26, 2021

\section{Keywords \\ COVID-19; Mortality; PM2.5; Subway/underground}

\section{Introduction}

A nationwide study by [1] in the United States indicated a connection between long-term exposure to particulate matter PM2.5 and COVID-19 related mortality [1]. COVID-19 had been found to be adherent to particulate matter and it has been suggested that PM2.5 is an airborne co-factor in COVID-19 infection [2]. PM2.5 minimum and maximum levels in subways have been found several times higher than surface level. An elevated mean PM2.5 concentration of 381 $\mu \mathrm{g} / \mathrm{m}^{3}$ was reported on the Victoria Underground, approximately 16 times higher than surface PM2.5 results [3]. The World Health Organization guideline recommends that PM2.5 levels should not exceed an average level of $25 \mu \mathrm{g} / \mathrm{m}^{3}$ 24-hour. The guideline stipulates that a PM2.5 concentration of $10 \mu \mathrm{g} / \mathrm{m}^{3} / 24 \mathrm{hr}$ is the lowest level at which combined cardiopulmonary and lung cancer mortality have been shown to rise in response to chronic exposure to PM2.5 [4]. Commuter use of underground rail is significant. On a global scale the use of transport via subways represents around $11 \%$ of worldwide public transport. In New York, the daily ridership is 5 million and decreased by $90 \%$ after the institution of the New York lockdown [5]. More than 200 million passengers commute daily in the 156 underground networks around the world. With the movement of rural populations to urban areas as in China, the ridership is increasing exponentially as in subways of Beijing and Shanghai.

\section{Methodology}

The mortality rate from COVID-19 related deaths was obtained from 18 cities. Due to variable rates of COVID-19 testing and diagnoses between countries and cities, mortality as a marker for COVID-19 incidence was used as it is a more robust indicator of the occurrence of COVID-19 infection. Cities were selected as opposed to nations, because substantial regional differences in infection rates have noted within the same countries. One group of these cities did not have an elevated percentage of the population that succumbed to COVID-19 deaths. This group consisted, of Tokyo, Naples, Sydney Vienna, Hong Kong, Seoul, Toronto, Athens and Taipei. The second group had significantly higher COVID-19 mortality rates and included Tehran, Barcelona, Stockholm, Sao Paolo, Wuhan, Paris, Milan, London and in New York. The mortality rates were obtained from various sources including the John Hopkins. Corona Virus Resource Centre and the WHO Coronavirus website. The cut-off for mortality rates between the cities was taken $0.05 \%$. There was a ten fold difference in the average mortality of both groups of cities. The maximum and minimum levels particulate matter PM2.5, were obtained for both groups of city subways from the literature pertaining to PM2.5 measurement. An important caveat is that measurements between stations from the same underground networks due to the age of the subway, the depth and length of the subway and the mode of its ventilation. Variation to PM2.5 also occurs with the network ridership, relative humidity and seasonal changes may also occur. Data regarding the underground networks of the city subways assessed were obtained from an internet site. The data retrieved included the number of stations, the length of the subway and the annual ridership for all networks.

\section{Results}

The percentage mortality of the individual's cities' population related to COVID-19 infection correlated significantly with the PM2.5 levels on the subway platforms. The correlation of the percentage population mortality with PM2.5 was significant for minimum PM2.5 levels $(\mathrm{p}<0.01)$ and highly significant for maximum $(\mathrm{p}<0.00001)$ levels of PM2.5 (Table 1). The PM2.5 levels differed significantly between both groups of cities differentiated by COVID-19 related mortality. The cities' subways with low COVID-19 death rates had minimum platform PM2.5 levels of $27.4\left(\mathrm{SD}+/-17.2 \mu \mathrm{g} / \mathrm{m}^{3}\right)$ compared to 63.4 $\mu \mathrm{g} / \mathrm{m}^{3}\left(\mathrm{SD}+/-10.8 \mu \mathrm{g} / \mathrm{m}^{3}\right)$ in cities with high COVID-19 associated mortality rates $(\mathrm{p}<0.01)$. Underground networks' maximum levels of PM2.5 in cities with low COVID-19 mortality was $53.4 \mu \mathrm{g} /$ $\mathrm{m}^{3}\left(\mathrm{SD}+/-21.8 \mu \mathrm{g} / \mathrm{m}^{3}\right)$ while that of subways with high COVID-19 mortality had maximum platform PM2.5 levels of $172.1 \mu \mathrm{g} / \mathrm{m}^{3}$ $\left(\mathrm{SD}+/-98 \mu \mathrm{g} / \mathrm{m}^{3}\right)(\mathrm{p}<0.001)$ (Tables $\left.1 \& 3\right)$. The length of the subway network and number of stations was significantly different between both groups of cities. The cities with higher COVID-19 death rates had longer networks $230 \mathrm{~km}(\mathrm{SD}+/-111 \mathrm{~km})$ versus $119 \mathrm{~km}(\mathrm{SD}+/$ $99 \mathrm{~km})(\mathrm{p}<0.03)$. Similarly cities with higher COVID-19 mortality rates had more stations 191 (SD+/-109) versus $102(\mathrm{SD}+/-94)$, showing significance $(\mathrm{p}<0.047)$. Although the annual ridership in the cities with the high COVID-19 mortality was higher (1034x106 versus $751 \times 106$ ), this did not achieve statistical significance (Tables 2\&4). The maximum PM2.5 correlated with the number of stations $(\mathrm{p}<0.045)$ and the length of the networks $(\mathrm{p}<0.044)$. The minimum PM2.5 did not achieve similar significant correlations. Ridership significantly correlated with number of stations $(\mathrm{p}<0.01)$ and the length of the network $(\mathrm{p}<0.02)$. 
Table 1: Low COVID related mortality as a percentage of the cities' population and the associated minimum and maximum levels of PM2.5.

\begin{tabular}{|c|c|c|c|}
\hline City & $\begin{array}{c}\text { COVID related \% Mortality of } \\
\text { population }\end{array}$ & $\begin{array}{c}\text { PM2.5 Minimum } \\
\mu \mathrm{g} / \mathbf{m}^{3}\end{array}$ & $\begin{array}{c}\text { PM2.5 Maximum } \\
\boldsymbol{\mu g} / \mathbf{m}^{3}\end{array}$ \\
\hline Tokyo & 0.0044 & 30 & 70 \\
\hline Naples & 0.0037 & 45 & 60 \\
\hline Sydney & 0.0028 & 15 & 61 \\
\hline Vienna & 0.011 & 38 & 47 \\
\hline Toronto & 0.0038 & 44 & 77 \\
\hline $\begin{array}{c}\text { Hong } \\
\text { Kong }\end{array}$ & 0.00005 & 24 & 50 \\
\hline Athens & 0.003 & 45 & 71 \\
\hline Seoul & 0.003 & 2.2 & 76 \\
\hline Taipei & 0.00003 & 3.8 & 59 \\
\hline Average & 0.0073 & 27.4 & 63.4 \\
\hline SD & 0.0119 & 17.2 & 10.8 \\
\hline
\end{tabular}

Table 2: Cities with low COVID related mortality and characteristics of subway networks assessed.

\begin{tabular}{|c|c|c|c|}
\hline City & No. of Stations & Length Km & Ridership/million \\
\hline Tokyo & 142 & 195 & 2266 \\
\hline Naples & 26 & 20 & 46 \\
\hline Sydney & 13 & 36 & 14 \\
\hline Vienna & 98 & 83 & 463 \\
\hline Toronto & 75 & 76 & 474 \\
\hline Hong Kong & 98 & 175 & 1805 \\
\hline Athens & 61 & 85 & 259 \\
\hline Seoul & 331 & 340 & 2155 \\
\hline Taipei & 119 & 140 & 789 \\
\hline Average & 102.6 & 119.4 & 750.6 \\
\hline SD & 93.7 & 99.1 & 906 \\
\hline
\end{tabular}

Table 3: High COVID related mortality as a percentage of the cities' population and the associated minimum and maximum levels of PM2.5.

\begin{tabular}{|c|c|c|c|}
\hline City & $\begin{array}{c}\text { COVID related \% } \\
\text { Mortality/population }\end{array}$ & $\begin{array}{c}\text { PM2.5 Minimum } \\
\boldsymbol{\mu g} / \mathbf{m}^{3}\end{array}$ & $\begin{array}{c}\text { PM2.5 Maximum } \\
\boldsymbol{\mu g} / \mathbf{m}^{3}\end{array}$ \\
\hline Tehran & 0.06 & 36 & 69 \\
\hline Barcelona & 0.1 & 46 & 125 \\
\hline Stockholm & 0.1 & 36 & 260 \\
\hline Sao Paolo & 0.07 & 52 & 78 \\
\hline Wuhan & 0.06 & 56 & 116 \\
\hline Paris & 0.057 & 65 & 121 \\
\hline Milan & 0.18 & 50 & 209 \\
\hline London & 0.089 & 105 & 371 \\
\hline New York & 0.089 & 35 & 200 \\
\hline Average & 0.089 & 53.4 & 172.1 \\
\hline SD & 0.368 & 21.8 & 98 \\
\hline
\end{tabular}

\section{Statistics}

The Statistical Package for Social Sciences (SPSS) was utilized to assess the data retrieved. The data was analysed for normality by the Kolmogoroff-Smirnov test and all the data except for the
Table 4: Cities with high COVID related mortality and characteristics of subway networks assessed.

\begin{tabular}{|c|c|c|c|}
\hline City & No. of Stations & Length Km & Ridership/million \\
\hline Tehran & 127 & 246 & 820 \\
\hline Barcelona & 133 & 122 & 412 \\
\hline Stockholm & 100 & 208 & 355 \\
\hline Sao Paolo & 89 & 101 & 1494 \\
\hline Wuhan & 201 & 339 & 1222 \\
\hline Paris & 302 & 214 & 1560 \\
\hline Milan & 106 & 96 & 369 \\
\hline London & 270 & 402 & 1384 \\
\hline New York & 424 & 380 & 1697 \\
\hline Average & 194.6 & 234.2 & 1034.7 \\
\hline SD & 115.2 & 117.8 & 550.1 \\
\hline
\end{tabular}

minimum PM2.5 and the length of the networks were found to be nonparametric. The Mann Whitney $U$ test was applied for comparing nonparametric variables of both groups of cities and the Spearman Rank test was applied for nonparametric correlations.

\section{Discussion}

This review article indicated that the minimum and maximum levels of PM2.5 in underground networks correlated with the population percentage mortality rates associated with COVID-19 infection. The correlation between the population percentage mortality progressively increased from minimum $(\mathrm{p}<0.01)$ to maximum $(\mathrm{p}<0.00001)$ levels of PM2.5. This pattern of significance may increase the biological plausibility of this correlation. Underground stations are characterized by the congestion of numerous commuters confined to an enclosed space in the presence of very high levels the pollutant PM2.5. Elevated PM2.5 levels in overcrowded platforms and train cabins may have synergized possibly making the subways prime sites for seeding COVID-19. PM2.5 concentrations in the London underground were found on average to be 18-times higher than concentrations at the surface. London underground levels of PM2.5 range from $39 \mu \mathrm{g} / \mathrm{m}^{3}$ to $734 \mu \mathrm{g} / \mathrm{m}^{3}$ on the deep tunnel lines and $14 \mu \mathrm{g} / \mathrm{m}^{3}$ to $368 \mu \mathrm{g} / \mathrm{m}^{3}$ for PM2.5 on the sub-surface lines [6]. In another study, the PM2.5 concentration in the London Underground (mean $88 \mu \mathrm{g} / \mathrm{m}^{3}$, median $28 \mu \mathrm{g} / \mathrm{m}^{3}$ ) was greater than at roadside environments (mean $22 \mu \mathrm{g} / \mathrm{m}^{3}$, median 14 $\mu \mathrm{g} / \mathrm{m}^{3}$ ). PM2.5 mass varied up to a magnitude of 90 between lines and locations, with the subsurface and deepest lines being the District (median $4 \mu \mathrm{g} / \mathrm{m}^{3}$ ) and Victoria (median $361 \mu \mathrm{g} / \mathrm{m}^{3}$ but up to $885 \mu \mathrm{g} /$ $\mathrm{m}^{3}$ ) respectively [6]. PM2.5 in underground networks is generated by several factors. These factors include friction between wheels and the rail and the braking mechanisms producing high levels of PM2.5. In this review the correlation between maximal PM2.5 with the number of stations supports the premise that braking mechanisms are responsible for high platform PM2.5 levels. Through the piston effect while trains travel through tunnels, the PM2.5 levels generated by wheel to rail friction would permeate the platform environment. This latter aspect would explain the PM2.5 correlation with the length of the subway networks. High concentration of PM2.5 is more likely in confined areas as in subways as opposed to the surface. Dispersal by wind and rain do not occur in the underground. The temporary 
piston effect when trains pass through tunnels may disperse platform air but it may also push tunnel air towards the platform. Air quality of underground platform depends on a variety of factors including ventilation, train speed and frequency, wheel materials and braking mechanisms, and station depth and design [7]. Several studies have shown adverse health impact associated with exposure to particulate matter PM2.5 [8,9]. Inhaled particulate matter has the propensity to create free radicals, which at the pulmonary epithelium may cause oxidative stress, resulting in negative health effects [10,11]. The metallic components of subway PM2.5 have been shown to cause oxidative stress in alveolar macrophage cells $[12,13]$. The health effects of subway PM2.5 can be assessed by measuring the oxidative potential of particulate matter by assessing two antioxidants commonly found at the surface of the lung, ascorbic acid and glutathione. This has been done by Moreno et al, whereby ascorbic acid oxidation and glutathione oxidation showed low levels of oxidative potential possibly due to copper, arsenic and antimony emanating from brake pads and pantographs. The ferrous component does not seem to have a significant effect on lung pathology [14]. An experimental model has suggested that intervention on subway human traffic would have limited effect on the transmission of respiratory infection [15]. The model simulated the interactions of underground commuters with various sites of their daily activities. This model-utilized information from the 1957-1958 H2N2 influenza epidemic and from New York City travel data. The model results indicated that the 1957-1958 pandemic had only a $4.4 \%$ contribution of influenza from subway interaction. This model concluded that public health interventions on the underground would have limited effect in containing the pandemic [15]. A crucial difference when comparing the 1957-58 influenza epidemic to COVID-19 is the reproduction number $\left(R_{0}\right)$ reflecting transmissibility of the viral infection. Whereas the $\mathrm{R}_{0}$ of the 1957-58 influenza epidemic was 1.1 at the beginning of 1957, the R0 of COVID-19 was estimated to be 3.28 in the initial stages [3]. This is substantially higher than the H2N2 in 1957 and also higher than Severe Acute Respiratory Syndrome (SARS) epidemic $\left(\mathrm{R}_{0}\right.$ 2.2) in 2003 [3]. During the severe acute respiratory syndrome 2003 SARS epidemic, the air pollution index was noted to correlate with mortality (Liu et al 2020). Patients who contracted SARS from Chinese provinces with high air pollution index had double the mortality compared to those from provinces with low air pollution index $(\mathrm{RR}=2.18,95 \% \mathrm{CI}$ : 1.31-3.65). More specifically to particulate matter, PM10 and PM2.5 were implicated in the transmission of the Avian flu in 1997 [16]. The above literature may suggest that the higher transmissibility of COVID-19 ( $\left.\mathrm{R}_{0} 3.28\right)$ may be due the presence of co-factors possibly including the utilization of particulate matter as a vector. COVID-19 genes have been found on particulate matter [2]. This study was carried out in the Bergamo region in Italy, which was hard hit with COVID-19 mortality and also reports an elevated level of particulate matter pollution for both PM10 and PM2.5. As opposed to control samples of particulate matter, 34 RNA extractions for the COVID-19 E, N and RdRP genes, demonstrated 20 positive results for one of the genes [2]. This study suggested that airborne transmission was further augmented by ambient particulate matter. It is therefore biologically plausible that in the significantly higher concentrations of PM2.5 found in subways, the mode of transmission was further accelerated in the presence of overcrowded commuters on station platforms and train cabins. This review indicated that subways in cities with high levels of COVID-19 mortality had significantly higher PM2.5 levels compared to cities with low deaths rates, which concomitantly had low levels of PM2.5. The network characteristics such as the number of stations and rail track length correlated with PM2.5 concentration. The study by [1] showed that long-term exposure to PM2.5 increases COVID-19 related mortality. Just an increase of $1 \mu \mathrm{g} / \mathrm{m}^{3}$ in long-term PM2.5 exposure correlated with an $8 \%$ increase in the COVID-19 death rate. In a previous study by the same authors on a large American population of 65-year-olds, the same small increment in long-term exposure to PM2.5 led to an increase of $0.73 \%$ in all-cause mortality. Consequently, for the same $1 \mu \mathrm{g} / \mathrm{m}^{3}$ increase in PM2.5, the magnitude of COVID related deaths increased eleven-fold [1]. The hypothesis of ambient salinity and the sodium chloride component in PM2.5 as a protective factor $[17,18]$ did not hold for the pandemic in the East Coast of USA. The states of New Jersey, Connecticut and Massachusetts have high levels of ambient salinity [19]. The role of subway interconnectivity and elevated PM2.5 levels may have eclipsed any protective factors causing high death rate in New York State [5] and the adjacent states of New Jersey, Connecticut and Massachusetts. Due to the high connectivity, New York, New Jersey and Connecticut are sometimes referred to as the Tristate. Beside the sodium chloride content of PM2.5, the carbon component of this particulate matter may also be involved in the pathogenesis of COVID-19. Whereas carbon is the major component of surface PM2.5, in subway PM2.5 is a minor constituent in subway PM2.5, with haematite being the more dominant element [20]. Carbon has adsorbant properties and possibly the lack of it in the haematite-rich subway PM2.5 may release the adherent virus more easily within the respiratory tract increasing COVID-19 pathogenicity. This review has a number of limiting factors. Firstly, although mortality related to COVID-19 infection is more robust that actual diagnosis of the infected cases, death rates also depend in part on the testing prevalence and variance of diagnoses, especially in the presence of multiple pathology. Moreover, mortality also depends on the social circumstances and education levels of the population, the accessibility of medical and preventive measures of the various cities and also the proportion of elderly and vulnerable in the cities' population. Social circumstances, educational background and preventive measures also impact the proportion of the population that indulges in tobacco smoking. The highest human exposure to particulate matter is through tobacco smoking. This article did not go into depth as regards the date and the effect of lockdown on COVID-19 infection and mortality. The implementation of national lockdown may have impacted the spread of infection however there was a spectrum of lockdowns throughout both groups of cities. Hong Kong and Seoul did not implement severely restrictive lockdowns. Both cities implemented tempestuous intervention to endorse mass testing and tracking. Moreover after the SARS epidemic the mindset of the people aided in adhering to physical distancing in all its different facets including the ubiquitous use of masks in subways and while travelling within train cabins $[21,22]$. Have shown that the use of masks are crucial in determining the spread of disease in Wuhan, Italy and New York. Face protection reduced the number of COVID-19 infections by more than 78,000 in Italy and over 66,000 in New York City during the months of April and May 2020 [22-40]. Other limiting factors may also have affected the variables assessed. The PM2.5 levels in various cities were taken prior to the COVID-19 
pandemic, during different seasons and years, and by different researchers and PM2.5 monitoring equipment. The studies showing adhesion of COVID-19 genes to particulate matter were related to surface measurements. The characteristics of the subway networks may have varied prior to the pandemic and some are undergoing structural changes that may affect PM2.5 levels

\section{Conclusion}

Overcrowded subways with elevated PM2.5 may expose commuters utilizing this mode of transport to higher viral loads adherent to particulate matter and consequent transmission. Combined with the adverse effects PM2.5 has on respiratory immunity, elevated subway PM2.5 levels in conjunction with inherent underground characteristics may possibly have increased COVID-19 infection spread and related mortality.

\section{References}

1. Wu X, Nethery RC, Sabath MB, Braun D, Dominici F. Exposure to air pollution and COVID-19 mortality in the United States: A nationwide crosssectional study. Department of Biostatistics, Harvard TH. Chan School of Public Health, Boston, MA, 02115, USA. MedRxiv. 2020.

2. Setti L, Passarini F, De Gennaro G, et al. Airborne Transmission Route of COVID-19: Why 2 Meters/6 Feet of Inter-Personal Distance Could Not Be Enough. Int J Environ Res Public Health. 2020; 17: 2932.

3. Liu Y, Gayle A, Wilder-Smith A, Rocklov J. The reproductive number of COVID-19 is higher compared to SARS coronavirus. J Travel Med. 2020.

4. WHO Air quality guidelines for particulate matter, ozone, nitrogen dioxide and sulfur dioxide. World Health Organization (September 2016), Ambient (outdoor) air quality and health: fact sheet, archived from the original on 2016. 2016.

5. Harris JE. The Subways Seeded the Massive Coronavirus Epidemic in New York City Department of Economics Massachusetts Institute of Technology Cambridge MA 02139 USA. 2020

6. Saunders BR, Smith J, Smith T, Green DC, Barrattt B. Spatial variability of fine particulate matter pollution (PM2.5) on the London Underground network. Urban Climate. 2019; 30: 100535

7. Moreno T, Perez N, Reche C, Martins V, de Miguel E, Capdevil M, et al. Subway platform air quality: assessing the influences of tunnel ventilation, train piston effect and station design. Atmos. Environ. 2014; 92: 461-468.

8. Brunekreef B, Holgate S. Air pollution and health. Lancet. 2002; 360: 12331242.

9. Pope C, Dockery D. Health effects of fine particulate air pollution: lines that connect. J Air \& Waste Manag Ass. 2006; 56: 709-742.

10. Kelly F. Oxidative stress: its role in air pollution and adverse health effects Occup. Environ Med. 2003; 60: 612-616.

11. Steenhof M, Gosens I, Strak KJ, Godri KJ, Hoek G, Cassee FR, et al. In vitro toxicity of Particulate Matter (PM) collected at different sites in The Netherlands is associated with PM composition, size fraction and oxidative potential-the RAPTES project Part. Fibre Toxicol. 2011; 8: 26

12. Jung HJ, Kim B, Malek M, Koo YS, Jung JH, Son YS, et al. Chemical speciation of size segregated floor dusts and airborne magnetic particles collected at underground subway stations in Seoul, Korea. J Hazard Mater. 2012; 213-214: 331-340.

13. Moreno T, Kelly JF, Dunster C. Oxidative potential of subway PM2.5. Atmospheric Environment. 2017; 148: 230-238.

14. Cooley P, Brown S, Cajka J, Chasteen B, Ganapathi L, Grefenstette J, et al. The Role of Subway Travel in an Influenza Epidemic: A New York City Simulation. J Urban Health. 2011; 88: 982-995.

15. Chen PS, Ta Tsai F, Kun Lin C, Yang CY, Chan CC, Young CY, et al. Ambient Influenza and Avian Influenza Virus during Dust Storm Days and Background
Days. 2010; 118: 1211-1216.

16. Baron YM. Covid-19 Pandemic in relation to PM2.5 and Ambient Salinity-An Environmental Wake-up Call. MedRXiv. 2020.

17. Baron M. Covid-19 and PM2.5 Sodium Chloride Content. Research Square. 2020.

18. Poma J. Salt Air: How far inland does salty air affect metals? 2018 Galvanizers Association. 2018.

19. Querol X, Moreno T, Karanaslou A, Reche C, Alastuey A, Viana M, et al. Variability of levels and composition of PM10 and PM2.5 in the Barcelona metro system June 2012. Atmospheric Chemistry and Physics. 2012; 12.

20. Park J. Changes in Subway Ridership in Response to COVID-19 in Seoul, South Korea: Implications for Social Distancing. Cureus. 2020; 12: e7668.

21. Zhang R, Li Y, Zhang AL, Yuan Wang Y, Molina MJ. Identifying airborne transmission as the dominant route for the spread of COVID-19. Proc Natl Acad Sci USA. 2020; 117: 14857-14863.

22. Pope CA, Burnett RT, Thun MJ, Calle EE. "Lung Cancer, Cardiopulmonary Mortality, and Long-term Exposure to Fine Particulate Air Pollution". 2002.

23. Tomoaki O. PM2.5 Yokohama subway Title: Investigation on the characteristics of particulate matter suspended in a subway station platform Authors: Okuda Y, Sakaide M, Fujioka K et al: Journal of Japan Society for Atmospheric Environment. 2019; 54: 28-33.

24. Cartenìa A, Cascetta F, Campana S. Underground and ground-level particulate matter concentrations in an Italian metro system. 2015.

25. Mohsen MF. Particulate Matter Emissions from Sydney Railway System: Concentration, Heavy Metal Content and Implications for Public Health. Thesis submitted for the degree of Master of Engineering (Research) for the University of Technology Sydney. 2017.

26. Posselt KP. Exposure to fine particulate matter in the Subway of Vienna. Diploma Thesis. Medical University of Vienna. 2018.

27. Van Ryswyk K, Anastasopolos AT, Evans G, Sun L, Sabaliauskas K, Kulka $\mathrm{R}$, et al. Metro Commuter Exposures to Particulate Air Pollution and PM2.5Associated Elements in Three Canadian Cities: The Urban Transportation Exposure Study. Environment Science and Technology. 2017

28. Zheng HL, Deng WJ, Cheng Y, Guo W. Characteristics of PM2.5, CO2 and particle-number concentration in mass transit railway carriages in Hong Kong June 2016. Environmental Geochemistry and Health. 2017; 39.

29. Martins V, Moreno T, Mendesc L, Eleftheriadisc K, Diapouli E, Alves CA, et al Factors controlling air quality in different European subway systems. Environ Res. 2016; 146: 35-46.

30. Choi S, Park JH, Kim SY, Kwak H, Kim D, Lee KH, et al. Characteristics of PM2.5 and Black Carbon Exposure Among Subway Workers, International Journal of Environmental Research and Public Health 2019. Int J Environ Res. Public Health. 2019; 16: 2901.

31. Cheng YH, Lin YL. Measurement of Particle Mass Concentrations and Size/ Distributions in an Taiwan Underground Station. Aerosol and Air Quality Research, Taiwan Association for Aerosol Research ISSN. 2010.

32. Kamani H, Hoseini M, Seyedsalehi M, Mahdavi Y, Jaafari J, Safari GH Tehran Concentration and Characterization of Airborne Particles in Tehran's Subway System. Environmental Science and Pollution Research. 2014; 21.

33. Johansson $\mathrm{C}$, Johansson PA. Particulate matter in the underground of Stockholm. Atmospheric Environment. 2003; 37: 3-9.

34. Camasmie Abe, Georges El Khouri Miraglia S. Health Impact Assessment of Air Pollution in São Paulo, Brazil International Journal of Environmental Research and Public Health. Int J Environ Res Public Health. 2016; 13: 694.

35. Lu H, Zhu H, Qi Y, Yu J. Do Wuhan Urban Subway Openings Reduce PM2.5 Concentrations? Evidence from China Sustainability. 2018; 10: 4147.

36. Raut JC, Chazette P, Fortain A. Metro air up to 30 times more polluted' than city's streets $1186 \pm 358(-401 \pm 66) \mu \mathrm{g} \mathrm{m}^{-2} \mathrm{~h}^{-1}$ Link between aerosol optical, microphysical and chemical measurements in an underground railway station in Paris. Atmospheric Environment. 2009; 43: 860-868. 
37. Ozgen S, Ripamonti G, Malandrini A, Raqettli MS, Lonati G. Particle numbe and mass exposure concentrations by commuter transport modes in Milan Italy. AIMS Environmental Science. 2016; 3: 168-184.

38. Adams HS, Nieuwenhuijsen MJ, Colvile RN, McMullen MA, Khandelwal P. Fine particle (PM2.5) personal exposure levels in transport microenvironments, London. UK Sci Total Environ. 2001; 279: 29-44.
39. Vilcassim MJR, Thurston GD, Peltier E, Gordon T. Black Carbon and Particulate Matter (PM2.5) Concentrations in New York City's Subway Stations. Environ Sci Technol. 2014; 48: 14738-14745.

40. Martins V, Moreno $\mathrm{T}$, Cruz M, van Drooge BL, Reche $\mathrm{C}$, Amato $\mathrm{F}$, et al Origin of inorganic and organic components of PM2.5 in subway stations of Barcelona, Spain. Environmental Pollution. 2016; 208: 125-136. 